\title{
Research Article \\ Iron deficiency anemia among rural population attending tertiary care teaching hospital
}

\author{
Sharadamani. G.S $\mathbf{S}^{1}$ \\ ${ }^{1}$ Dr. Sharadamani. G.S., Associate Professor, Department of Pathology, Vinayaka Missions Medical College \&Hospital, \\ Karaikal- 609609, Puducherry, India.
}

Address for Correspondence: Dr. Sharadamani.G.S, Email: smanibmc@ gmail.com

\begin{abstract}
Background: Nutritional anemia is a major public health problem in India and is primarily due to iron deficiency which is more common among rural population. The present study aimed at evaluating iron deficiency anemia among rural population attending our tertiary care teaching hospital. Materials and Methods: Patients having hemoglobin level below $11 \mathrm{~g} / \mathrm{dl}$ with Serum Iron level $<30 \mathrm{ug} / \mathrm{dl}$ and/or serum TIBC $>400 \mathrm{ug} / \mathrm{dl}$ were enrolled in the study. A total of 259 patients were included in the study. Hemoglobin estimation and other investigations were performed as per standard protocol in pathology laboratory. Results: Majority of patients were females (58.69\%) and preponderance of iron deficiency anemia was seen in the age group of 21-30 (28.96\%) followed by 31-40 (25.09\%). Majority of male patients had mild anemia (55.14\%) whereas majority of females had moderate anemia (57.24\%). Conclusion: Iron deficiency anemia is significantly high among women of reproductive age group. Among females moderate anemia was predominant. Mild anemia was commonly observed in males.
\end{abstract}

Key words: Iron deficiency anemia, Rural population, Reproductive age group

\section{Introduction}

Anemia is an abnormal physiological and hematological condition concerned with reduction in oxygen carrying capability of the blood due to decline in Red Blood Cell (RBC) count, Packed Cell Volume (PCV) and Hemoglobin $(\mathrm{Hb})$ concentrations than normal ranges [1]. Anemia is a major global health problem, especially in developing countries like India. Anemia can be of various types based on the morphology of the RBCs depending on etiology and clinical aspect.

Manuscript received: $7^{\text {th }}$ January 2017

Reviewed: $13^{\text {th }}$ January 2017

Author Corrected: $21^{\text {st }}$ January 2017

Accepted for Publication: $30^{\text {th }}$ January 2017
$30 \%$ or nearly one third of world's population is suffering from anemia due to various causes [2]. The most common being deficiency of essential elements for the synthesis of hemoglobin (Iron, Vitamin B12 and Folic Acid), blood loss, repeated pregnancies in females of reproductive age, worm infestation, hemolysis due to known or unknown causes and bone marrow conditions causing suppression of red cell synthesis. Chronic diseases such as chronic renal failure, rheumatoid arthritis and tuberculosis are also known causes [3]. Iron deficiency anemia is a major nutritional problem in 
India and many other developing countries. The importance of iron-deficiency as cause of anemia varies by region. Prevalence of iron deficiency anemia is higher in India than other developing countries [4].

According to the statistics of the World Health Organization (WHO) [5], the prevalence of anemia is $48 \%$ in preschool-age children (less than 5 years of age), $25 \%$ in school-age children (5 to 14 years), $13 \%$ in males (15 to 59 years), $42 \%$ in pregnant females, $30 \%$ in women of reproductive age (15 to 49 years), and $24 \%$ in the elderly ( $>60$ years).

It is of note that anemia is particularly prevalent among three population groups, i.e., preschool-age children, pregnant females, and women of reproductive age [4].

Consequences among pregnant women include, abortions, premature births, post-partum hemorrhage and low birth weight were especially associated with low hemoglobin.

Anemia among pre school children and school going age group is predominantly due to parasitic diseases such as maiaria and worm infestations.

Iron deficiency anemia may impair the activity of host defense mechanisms and make host more prone to infections. Further it causes decrease in working capability of the individual [4].

Hence, we aimed at evaluating anemia among various age groups and proportion of iron deficiency anemia in mild, moderate and severe anemic patients.

\section{Materials and Methods}

This is a prospective, observational study conducted in the department of pathology, Vinayaka Mission's
Medical College and Hospital. A total of 259 iron deficiency anemia patients were included in the study. Venous blood collected from the patients included in the study after obtaining verbal consent.

Hb level, total erythrocyte count, red cell indices such as mean corpuscular volume (MCV), mean corpuscular haemoglobin $(\mathrm{MCH})$ and mean corpuscular haemoglobin concentration (MCHC); and white cell indices such as total leucocyte count (TLC) and differential leucocyte count, as well as platelet count, packed cell volume and reticulocyte count were performed using automated analyser (HORIBA MICROS ES 60).

Further bone marrow study was also performed by using Prussian blue reaction. Peripheral smear was made and examined for microscopic findings. Iron studies included serum iron and total iron binding capacity (TIBC).

Inclusion criteria: Hemoglobin level below $11 \mathrm{~g} / \mathrm{dl}$ with Serum Iron level $<30 \mathrm{ug} / \mathrm{dl}$ and/or serum TIBC $>400$ $\mathrm{ug} / \mathrm{dl}$ were included in the study.

Exclusion criteria: Patients having history of taking supplemental iron during previous year, history of blood transfusion, family history of anemia, history of receiving oral contraceptive pills were excluded from the study.

The level of $\mathrm{Hb}$ in different categories of anemia was defined as follows: (i) severe anemia $<7 \mathrm{~g} / \mathrm{dl}$, (ii) moderate anemia 7-9.9 g/dl, (ii) mild anemia in pregnant women 10-10.9 g/dl, and (iv) mild anemia in non-pregnant women 10-11.9 g/dl.[5].

Statistical analysis: Analysis of results was performed by simple percentage method. 


\section{Results}

A total of 259 patients were included in the study. Out of them 107(41.31\%) were males and 152(58.69\%) were females. Majority of patients were belonged to the age group of 21-30(28.96\%) followed by 31-40(25.09\%). The average hemoglobin was $7.5 \mathrm{gms}$.

The lowest hemoglobin recorded in our study was $3.5 \mathrm{gms}$. In males, the prevalence of iron deficiency was $4.25 \%$ in ages 1 to 10 years, $5.02 \%$ in 11 to 20 years.

Majority of male patients were belonged to the age group of 31-40 and accounted for $10.42 \%$. In females, the prevalence of iron deficiency was highest in the age group of 21-30 and accounted for (28.96\%). (Table.1)

Table-1: Age and gender wise distribution of Iron deficiency anemia.

\begin{tabular}{|c|c|c|c|c|}
\hline S. No & Age & Males (\%) & Females (\%) & Total (\%) \\
\hline 1 & $0-10$ & $11(4.25)$ & $6(2.31)$ & $17(6.56)$ \\
\hline 2 & $11-20$ & $13(5.02)$ & $14(5.40)$ & $75(10.42)$ \\
\hline 3 & $21-30$ & $19(7.34)$ & $56(21.62)$ & $65(25.09)$ \\
\hline 4 & $31-40$ & $27(10.42)$ & $17(6.56)$ & $29(11.20)$ \\
\hline 5 & $41-50$ & $12(4.63)$ & $14(5.40)$ & $21(8.10)$ \\
\hline 6 & $51-60$ & $7(2.70)$ & $11(4.25)$ & $25(9.65)$ \\
\hline 7 & $>60$ & $14(5.40)$ & & \\
\hline
\end{tabular}

Severity of anemia was categorized into mild, moderate and severe. Majority of male patients had mild anemia whereas moderate anemia was predominated among females. Least number of patients had severe anemia in both males and females. (Table.2)

Table-2: Distribution of iron deficiency anemia in males and females

\begin{tabular}{|c|c|c|c|}
\hline S. No & Category & Males & Females \\
\hline 1 & Mild & $59(55.14 \%)$ & $47(30.92 \%)$ \\
\hline 2 & Moderate & $35(32.71 \%)$ & $87(57.24 \%)$ \\
\hline 3 & Severe & $13(12.15 \%)$ & $18(11.84 \%)$ \\
\hline
\end{tabular}

In our study, 69 pregnant women were identified with iron deficiency anemia. Majority of pregnant women were belonged to the age group of 21-25 which accounted for $52.17 \%$.

Iron deficiency anemia was $40.28 \%$ in Primi gravida and 59.42\% in multi gravid. Majority of pregnant women (46.38\%) in third trimester had anemia (Table.3) 
Research Article

Table-3: Profile of iron deficiency anemia in pregnant women.

\begin{tabular}{|c|c|}
\hline Age & No. of patients (\%) \\
\hline $15-20$ & $10(14.49)$ \\
\hline $21-25$ & $36(52.17)$ \\
\hline $26-30$ & $17(24.64)$ \\
\hline $31-35$ & $6(8.70)$ \\
\hline Gravida & $28(40.58)$ \\
\hline Primi & $41(59.42)$ \\
\hline Multi & $15(21.74)$ \\
\hline Trimester & $22(31.88)$ \\
\hline First & $32(46.38)$ \\
\hline Second & \\
\hline Third & \\
\hline
\end{tabular}

\section{Discussion}

Anemia can be of various types, but most common in developing countries is nutritional anemia. Globally anemia due to iron deficiency is perhaps the most widespread clinical nutritional deficiency disease especially among rural population. In our study, the age group of 21-40 years had highest prevalence of anemia. This is in agreement with the studies conducted previously $[6,7]$.

However, another study from South India reported 4045 years age group as predominant [8]. Another study conducted by Lamsal, showed highest prevalence in 40 49 years age group [9].

In the present study anemia were in elderly $9.65 \%$, in contrast another community based study conducted by Swami et al. showed high prevalence of anemia among elderly(68.5\%), this difference may be due to our study is hospital based[10].

Similarly other Indian studies also showed varying degree of anemia depending on difference in various variables. The relation of anemia and age was different for various locations. In the present study, females were predominated and accounted for 152(58.69\%) whereas males accounted only for $107(41.31 \%)$.

This is in accordance with the study conducted by Reena kouli et al[11], who reported $39.92 \%$ males and $60.08 \%$ females. However, other studies showed no statistical difference between both genders $[12,13]$. This is in contrast with the study conducted by Chul won choi et al [14].

To explain the variations in prevalence rates of anemia, few researchers argued that estrogens act as inhibitors of erythropoiesis and make women more vulnerable to the development of anemia.

However, while postmenopausal estrogen levels decrease, there is an increase in red cell mass to levels that are similar to those in males, which makes it unreasonable to use different criteria for anemia in each gender [15].

In our study, majority of male patients had mild anemia 59(55.14) and majority of females had moderate anemia 87(57.24). Prevalence of severe anemia was least in both genders. According to Agarwal et al[16]. Who 
Research Article

reported prevalence of moderate anaemia to be maximum (50.9\%) followed by mild (34\%) and severe anaemia (7.3\%). Taseer et al [17] reported only mild and moderate anaemia cases and no severe anaemia case.

Majority of pregnant women with iron deficiency had moderate category of anaemia. According to Abel et al [18], maximum number of cases were classified as moderate anemia $(35.8 \%)$ and minimum number of cases were classified as severe anemia (3.3\%) which is in agreement with the present study. Similarly, Ahmad et al [19], reported maximum number of cases were classified as moderate anemia(50.9\%) and minimum number of cases were classified as severe anemia(18.9\%).

In India, special attention is given towards moderate to severe forms of anemia because of its high prevalence and the public health significance of moderate and severe anemia [20]. In the present study, demographic data obtained was limited.

However, previous studies showed significant association between low education and socio economic strata. According to Shweta rajput et al [21], 98.9\% women in lower socioeconomic strata had iron deficiency anaemia as compared to $14.3 \%$ women in upper socioeconomic strata.

Females belongs to lower socioeconomic strata have limited access to nutritious diet. They generally follow normal diet and normal activity schedule despite in pregnant state. Ignorance, poverty and gender bias significantly contribute to this high prevalence [21].

In our study, majority of patients complained generalized weakness, breathlessness and puffiness of face, nail brittleness. In a study conducted by Ratre et al[22], most common symptoms were fatigability
(100\%), decreased work performance (80\%), breathlessness on exertion $(60 \%)$, other important presenting symptoms were swelling over body (40\%), pain in abdomen (40\%), bodyache (28\%), giddiness (20\%), palpitation $(20 \%)$, headache $(12 \%)$, anorexia (10\%), worms in stool (10\%), PICA (8\%) and chest pain $(5 \%)$.

Weakness, fatigability, decreased work performance and dyspnea on exertion were common symptoms, which were because of cardiovascular compromise. Work capacity is assessed by aerobic capacity, endurance, energetic efficiency, voluntary activity and work productivity.

The presumed mechanism for this effect is the reduced oxygen transport associated with anemia; tissue iron deficiency may also play a role through reduced cellular oxidative capacity. Iron plays an essential role in oxidative energy production [22].

Higher rate of parasitic infestations were observed in our study. Stool examination was performed for the detection of intestinal parasites in 95 patients, but not in all which remained as one of the limitations of the study.

In 27 stool specimens ova of hook worm was seen. Cysts of Entamoeba histolytica were seen in 8 stool specimens and two stool specimens with Giardia lamblia trophozoites were seen.

No other intestinal parasites were detected. But previous studies reported, Ascaris lumbricoides and Trichuris trichiura[23].

Ancylostoma duodenale and Necator americanus are two important species of hook worm which contribute to iron deficiency anemia [23]. In the present study, hook worm Ancylostoma duodenale alone was reported. 
However, stool concentration techniques are more accurate than routine stool examination for the diagnosis of intestinal parasites. Other infectious diseases commonly associated with anemia, like leishmaniasis and schistosomiasis, are nonexistent in the area.

Least number of malaria cases has been reported from this region. In our study, two cases of Plasmodium vivax were seen in peripheral smear. Few studies associated urinary tract infections with anemia and an elevated s-CRP [24].

Various studies reported anemia as a common complication of pulmonary tuberculosis [25]. A number of studies in India, Indonesia, South Korea, Nigeria have documented anemia in patients with TB, however, all the studies involved only small numbers of patients and the results were not uniform[26].

\section{Conclusion}

Iron deficiency anemia is significantly high among women of reproductive age group. Preponderance of moderate anemia was seen in females and mild anemia was commonly observed in males.

Effective public health education, school based deworming and promoting cost effective iron rich diet among rural population would help in reducing the incidence of iron deficiency anemia.

Funding: Nil, Conflict of interest: None initiated,

Permission from IRB: Yes

\section{References}

1. CamaschellaC. Iron-deficiency anemia. $\mathrm{N}$ Engl J Med. 2015; 372(19):1832-43. DOI: 10.1056/ NEJ Mra 1401038 .
2. Khambalia AZ, Aimone AM, Zlotkin SH. Burden of anemia among indigenous populations. Nutr Rev. 2011; 69(12):693-719.

3. Muhammad Idris, Anis-ur-Rehman.Iron deficiency anaemia in moderate to severely anaemic patients. $\mathbf{J}$ Ayub Med Coll Abbottabad 2005;17(3):45-7.

4. Gupta SK, Agarwal SS, Kaushal R, Jain A, Gupta VK, Khare N. Prevalence of Anemia among rural population living in and around of rural health and training center, Ratua Village of Madhya Pradesh. Muller J Med Sci Res 2014;5(1)15-8.

5. De Benoist B, McLean E, Egli I, Cogswell M, eds. Worldwide prevalence of anaemia 1993-2005. WHO global database on anaemia. Geneva, Switzerland: WHO Press, 2008:1-40.

6. K. C. Menon, S. A. Skeaff, C. D. Thomson et al., Concurrent micronutrient deficiencies are prevalent in nonpregnant rural and tribal women from central India, Nutrition 2011; 27( 4): 496-502.

7. P. Thankachan, S. Muthayya, T. Walczyk, A. V. Kurpad, and R. F. Hurrell-An analysis of the etiology of anemia and iron deficiency in young women of low socioeconomic status in Bangalore, India, $\|$ Food and Nutrition Bulletin 2007; 28 ( 3): 328- 36.

8. Raghuram V, Manjula Anil, Jayaram S. Prevalence of anaemia amongst women in the reproductive age group in a rural area in south india. International Journal of Biological \& Medical Research 2012; 3(2):1482-4.

9. K.S.Lamsal.Clinical profile of patients with anemia. Journal of Institute of Medicine,2009;31(3):31-6. 
10.Swami HM, Bhatia V, Dutt R, Bhatia SP. A community based study of the morbidity profile among the elderly in Chandigarh, India. Bahrain Med Bull 2002; 24(1):13-6.

11. Reena Kouli, Ajit Kumar Pegu, Jasmine Teronpi, Ranu Shukla, Samrat Bhattarcharjee, Sima Sonowal,

Vishal Agarwal, Kamal Kishore Chelleng. Study of Anaemia in Correlation with Hematological Parameters among Adults in a Tertiary Care Centre of North-East India. Int J Med Res Prof. 2016; 2(4):84-7.

12. Kaur H,Piplani S, Madan M. Prevalence of anemia and micronutrient deficiency in elderly.International Journal of Medical and Dental Science. 2014; 3(1): 296-302.

13. Nasrin A. Qureshi, Mohammed Abid Z. Chauhan, A.P. Goswami, S.K Suri. Study of anemia and its correlation with Hematological parameters in patient of various age group. IOSR Journal of Dental and Medical Sciences (IOSR-JDMS). 2015;14(9):29-35.

14. Choi CW, Lee J, Park KH, Yoon SY, Choi IK, Oh SC. Prevalence and Characteristics of Anemia in the Elderly: Cross-Sectional Study of Three Urban Korean Population Samples. Am J Hematol 2004; 77(1): 26-30.

15. Sahadevan S, Choo PW, Jayaratnam FJ. Anaemia in the hospitalized elderly. Singapore Med J. 1995; 36 (4):375-8.

16. Agarwal KN, Agarwal DK, Sharma A, Sharma K, Prasad K, Kalita MC, Khetrapal N, Kapoor AC, Vijayalekshmi L, Govilla AK, Panda SM, Kumari P. Prevalence of anaemia in pregnant \& lactating women in India. Indian J Med Res 2006; 124: 173-84.
17. Taseer IUH, Mirbahar A, Safdar S, Awan Z. Anemia in Pregnancy: Related risk factors in underdeveloped area. Professional Med J Mar 2011; 18(1): $1-4$

18. Abel R,Rajaratnam J,Gnanasekaran VJ and Jayraman P.Prevalence of anemia and iron deficiency in three trimesters in rural vellore district,South India. Trop. Doct. 2001;31(2):86-9.

19. Ahmad N, Kalakoti P, Bano R, Syed MMA. The prevalence of anaemia and associated factors in pregnant women in a rural Indian community. AMJ. 2010; 3( 5),: 276-280 Doi 10.4066/AMJ.2010.286.

20. R. J. Stoltzfus. Defining iron-deficiency anemia in public health terms: a time for reflection. Journal of Nutrition.2001;131(2):565-7.

21. Rajput S, Singh MK. Iron Deficiency Anaemia and Its Predisposing Causes among Women Undergoing Antenatal Checkup at a Tertiary Care Hospital in Allahabad. Ntl J Community Med 2016; 7(6):480-4.

22. Ratre BK, Patel NP, Patel U, Jain R, Sharma VK. Clinical and Epidemiological profile of Anemia in central India. Int J Med Res Rev 2013;2(1):45-52

23. Crompton DW. How much human helminthiasis is there in the world? J Parasitol 1999;85(3):397-403.

24. Hinderaker SG, Olsen BE, Bergsjø PB, Lie RT, Gasheka P \& $\mathrm{Kva}^{\circ} \mathrm{le} \mathrm{G}$. Anemia in pregnancy in the highlands of Tanzania. Acta Obstet. Gynecol. Scand. 2001; 80(1):18- 26.

25. Das BS, Devi U, Mohan Rao C, Srivastava VK, Rath PK, Das BS. Effect of iron supplementation on mild to moderate anaemia in pulmonary tuberculosis. Br J Nutr. 2003; 90(3):541-50. 
26. Lee SW, Kang YA, Yoon YS, Um SW, Lee SM, Yoo CG, Kim YW, Han SK, Shim YS, Yim JJ: The prevalence and evolution of anemia associated with tuberculosis. $J$
Korean Med Sci. 2006, 21: 1028-32. 10.3346 /jkms. 2006.21.6.1028.

\section{How to cite this article?}

Sharadamani. G.S. Iron deficiency anemia among rural population attending tertiary care teaching hospital. Trop J Path Micro 2017;3(1):01-08.doi: 10.17511/jopm.2017.i1.01 